\title{
A Bibliometric Analysis of Published Articles on Management Information Systems (MIS)
}

\author{
$1,{ }^{*}$ Faraj Salman Alfawareh \\ School of Economics, Finance and Banking, Universiti Utara Malaysia. \\ Email: faraj.salman@yahoo.com (*Corresponding author) \\ ${ }^{2}$ Mahmoud Al-Kofahi \\ Faculty of Administrative and Financial Sciences, Irbid National University, Jordan. \\ Email: $\underline{\text { m.kofahi@inu.edu.jo }}$ \\ ${ }^{3}$ Bara'a Al-Kofahi \\ Deanship of Educational Services/Computer science unit, Qassim University, Saudi Arabia. \\ Email: Baraakofh@qu.edu.sa \\ ${ }^{4}$ Malek Hamed Alshirah \\ Accounting Department, Al al-Bayt University, Jordan. \\ Email: shraamalek@gmail.com \\ ${ }^{5}$ Mohammad Alshira'h \\ Department of Information Systems, Al al-Bayt University, Jordan. \\ Email: alshirah@aabu.edu.jo \\ ${ }^{6}$ Husam Ananzeh \\ Faculty of Administrative and Financial Sciences, Irbid National University, Jordan. \\ Email: H.ananzeh@inu.edu.jo
}

\begin{abstract}
This paper aimed to explore trends in management information systems (MIS) research from 2017 to 2021 and compare their contributions based on different countries and authors. In particular, this study presents a bibliometric analysis of MIS highlighting key themes including, effective top MIS journals, authors, contributing countries, source types, sponsoring institutions, document languages, and subject areas, within the past five years. The data were chosen from Web of Science and Scopus databases based on defined search terms relating to MIS. Microsoft Excel 2016 was used to summarize bibliometric features, including the number of publications, subject areas and country contributions. Based on the search results, a total of 3624 papers were included. The results showed that most of the articles were published in journals and conferences, mainly in English. Additionally, most of the research in MIS was in the computer, engineering, medicine and management sciences fields and China contributed the largest percentage of articles (17\%). The "Journal of Physics" and the "International Conference on Information Systems Development" had the highest publication number, while, the European Commission, the National Natural Science Foundation of China, and the National Science Foundation were the top funding institutions. The outcomes provide a global perspective of the MIS field, identifying the works that have had the greatest impact, the main study traditions or themes that have been explored in MIS studies. Structural analyses revealed changes in the MIS over time. The paper concluded with suggestions and accumulated knowledge for future study.
\end{abstract}

Keywords: Bibliometric analysis, Information Systems, Management Information Systems, MIS field.

DOI: $10.7176 / \mathrm{IKM} / 11-4-14$

Publication date:November $30^{\text {th }} 2021$

\section{Introduction}

The understanding concerning an organization's relative position and basic working forces is provided by the Management Information Systems (MIS). Via MIS, the correct information for making decisions is provided to facilitate the organization's control, planning and carrying out operational functions successfully (Mishra et al., 2015). Studies on MIS only began about 50 years ago but significant progress has been achieved in the field, with continuous growth and development so as to cater to the business and marketing environment's shifting 
requirements (Palvia et al., 2003; Straub et al., 2010). Scholars and practitioners continue to enrich the MIS field by disseminating their insight and knowledge via academic journals. Trends and transformations that affect the theories, processes and applications of MIS can therefore be identified by studying such journals (Al-Kofahi et al., 2020; El-Ebiary et al., 2021; Özköse \& Gencer, 2017). In addition, MIS enriches various business functions and could prove to be crucial for analyzing data that facilitates decision making (i.e., becoming a support system for making decisions) (Davis, 1999). Hence, this current study aims to bibliometrically analyze the MIS field through assessing the productivity of MIS researchers, specifically by examining the most frequent publishers of MIS articles, the most productive authors, contributing countries, source types, sponsoring institutions, document languages, and subject areas.

This study has five sections. Following the introduction and the study objective, Section two presents the review of literature, Section three provides a brief explanation of the study methodology, whilst Section four presents the discussion of findings. Section five concludes the paper.

\section{Literature Review}

Management Information Systems (MIS) is still at its infancy as an academic discipline and area of study, enriched by its specific history and tradition (Culnan \& Swanson, 1986). It focuses on the application of numerous information technologies strategically, managerially and operationally at the level of the society, organization, and individual. It is based on various disciplines including computer science, behavioral science, decision science, cognitive psychology, operation management, organization theory as well as engineering (Katerattanakul et al., 2006). From its inception, MIS researchers have investigated the field's development in the past, at present and in the future.

MIS research frameworks emerged in the 1980s, with MIS conceptualized as "a computer-based organizational information system which provides support for management activities and functions" (Ives et al., 1980). Studies had been conducted on the advancement of MIS research via author co-citation analysis (Culnan,1987). The field of MIS became a formal discipline in the 1990s when the keyword classification scheme for MIS literatures was developed (Barki et al., 1993). Although it has been around for over three decades, MIS still has not developed its own identity as a reference discipline, a situation mainly caused by the constant changes in research directions and technological innovations. MIS research trends had been studied and it was found that primary focus is on the aspects of information system (IS) usage and IS resource management. However, the field is on the verge of maturity as indicated with the usage of more rigorous research approaches including mathematical models and lab experiments (Palvia et al., 2007). MIS academic identity is unfolded through two key intellectual cores, namely IT Artifact and IS theme. Recent scholars have also begun to explore literatures presented in conferences. The MIS field has been developing its identity through the use of a scientometric perspective executed in key MIS conferences held globally, regionally and nationally, which indicated the evolution of the MIS field in the aspect of collaborative research and academic output, leading to academic maturity as well as loyalty to several academic meetings (Mohanty \& Sahoo, 2016). The impact of MIS was proven to be highly significant in a study that assessed the mutual and shared effect of MIS (Mohanty, 2014).

Moreover, Merigo et al. (2018) conducted a review of the $50^{\text {th }}$ anniversary of IS, within which publication and citations of journals were enumerated through graphical analysis, rather than thematic analysis. Similarly, La Paz et al. (2020) reviewed the $25^{\text {th }}$ IS Journal anniversary adopting an ontological review and concentrating on the research type as opposed to themes, while Culnan's (1987) presentation of MIS Quarterly followed an intellectual structure. Other studies like $\mathrm{Hu}$ et al. (2002) studied the holdings of IS journals in university libraries and listed the number of journals that each university offers concerning MIS degrees. The universities were categorized into the highest degree provided with individual journal titles ranked based on the overall number of university libraries that presented the title. In this regard, the titles are publication outlets for MIS that had no information on the scope of materials utilized for the research production. On the whole, studies that provide fundamental literature and research themes in online reviews of MIS are still lacking and as such, the present study reviews recent publications in the dynamically expanding field as evidenced by the fact that majority of the works were published in the past five years. Lastly, this work presents a novel thematic evolution chart and the analysis of network structure dimensions, enabling for a deeper insight into the field's development and status.

\section{Methodology}

According to Pritchard (1969), the bibliometric approach studies bibliographic contents quantitatively. It typically summarizes the pertinent results of bibliographic documents (Martinez-Lopez et al., 2018). AlbortMorant et al. (2017) asserted that a bibliometric analysis reveals the past and provides insights of research progress. This approach has also been employed in other fields including advertising (Punjani et al., 2019), 
education (Diem \& Wolter, 2013), manufacturing (Ahmi et al., 2019), and medicine (Zhai et al., 2017). A number of journals have also recently applied this approach to come up with an overview of their published articles. So, the study data was gathered from Scopus database using a systematic and organized process. The reason behind Scopus selection lies in its recognized index with an extensive coverage of peer-reviewed publications and its bibliographic data reliability (Martin-Martin et al., 2018). The keywords used in the search queries were relevant words in the MIS field, for years spanning from 2017 to 2021 . Hence, by using Scopus databases, the search strategy included the term "management information systems" (as it appears in article title, keywords, or abstract) and published within the timeframe of 2017 to 2021 . Based on the search results, a total of 3624 papers were included. Microsoft Excel 2016 was used to summarize bibliometric features. In other words, this paper employs the approach in analyzing MIS trends.

\section{Findings and Discussions}

\subsection{The most frequent publishers}

From 2017 to 2021, several articles were identified from academic journals and international conferences on a similar theme as represented in Table 1 below. This includes the International Conference on Information Systems Development, and the International Conference on Pervasive Computing Technologies for Healthcare. Similarly, several major journals, such as the MIS Quarterly: Management Information Systems, and Advances in Intelligent Systems and Computing have done so. All these display the varied and extensive publishing scenario for MIS researchers.

Table 1. The most frequent publishers of MIS articles

\begin{tabular}{|l|l|c|}
\hline No & \multicolumn{1}{|c|}{ Journal /Conference Name } & No. of Articles \\
\hline $\mathbf{1}$ & Journal Of Physics: Conference Series & 166 \\
\hline $\mathbf{2}$ & International Conference on Information Systems Development & 162 \\
\hline $\mathbf{3}$ & ACM International Conference Proceeding Series & 149 \\
\hline $\mathbf{4}$ & Advances in Intelligent Systems and Computing & 140 \\
\hline $\mathbf{5}$ & Lecture Notes in Business Information Processing & 112 \\
\hline $\mathbf{6}$ & International Conf. on Pervasive Computing Technologies for Healthcare & 99 \\
\hline $\mathbf{7}$ & Ceur Workshop Proceedings & 72 \\
\hline $\mathbf{8}$ & MIS Quarterly: Management Information Systems & 63 \\
\hline $\mathbf{9}$ & Lecture Notes in Computer Science & 56 \\
\hline $\mathbf{1 0}$ & Procedia Computer Science & 45 \\
\hline
\end{tabular}

\subsection{Effective authors}

Table 2 presents the $10 \mathrm{key}$ authors and the number of their publications contributing to the MIS field. The names of the authors are written in various formats. Each author's name was verified to identify their publication frequency; however, this may not reveal the actual figures. As shown in Table 2, the top MIS authors are Zawiyah M. Yusof with 9 articles published in this period; Andy Pavlo, Thomas Seidl and Marcin Hernes with 8 articles for each author; Louise Day, Joy Lawn, Harriet Ruysen and Nahya Salim with 7 articles for each author. Their contributions are highly noteworthy being the leaders and pioneers in the field.

Table 2. Most productive authors

\begin{tabular}{|l|l|c|c|}
\hline No & Prolific authors & Authors Affiliations & No. of Articles \\
\hline $\mathbf{1}$ & Zawiyah M. Yusof & UniversitiKebangsaan Malaysia & 9 \\
\hline $\mathbf{2}$ & Andy Pavlo & Carnegie Mellon University & 8 \\
\hline $\mathbf{3}$ & Thomas Seidl & LMU Munich & 8 \\
\hline $\mathbf{4}$ & Marcin Hernes & UniwersytetEkonomiczny we Wrocławiu & 8 \\
\hline $\mathbf{5}$ & Louise T. Day & London School of Hygiene \& Tropical Medicine & 7 \\
\hline $\mathbf{6}$ & Joy E. Lawn & London School of Hygiene \& Tropical Medicine & 7 \\
\hline $\mathbf{7}$ & Harriet Ruysen & London School of Hygiene \& Tropical Medicine & 7 \\
\hline $\mathbf{8}$ & Nahya Salim & Muhimbili Uni. of Health \& Allied Sciences & 7 \\
\hline $\mathbf{9}$ & Donat Shamba & Ifakara Health Institute & 6 \\
\hline $\mathbf{1 0}$ & Roman Lukyanenko & HEC Montréal & 6 \\
\hline
\end{tabular}




\subsection{Effective countries}

The results of this study show that 173 countries are listed to have contributed to the MIS field. A total of 26 countries contributed the most. Another 57 countries contributed 10 publications and lower. The analysis also indicates that the top 10 effective countries in the MIS field contributed $68 \%$ of the total publications. As indicated, China contributed 623 MIS-related articles representing $17 \%$ of the studies, followed by USA with 537 studies (15\%), Indonesia with 294 studies (8\%), and Germany with 211 studies (6\%). The result also indicates that MIS articles can be examined by various countries, leading to accelerated growth in the field of MIS. Figure 1 presents the top effective countries and the number of their publications contributing to the MIS field.

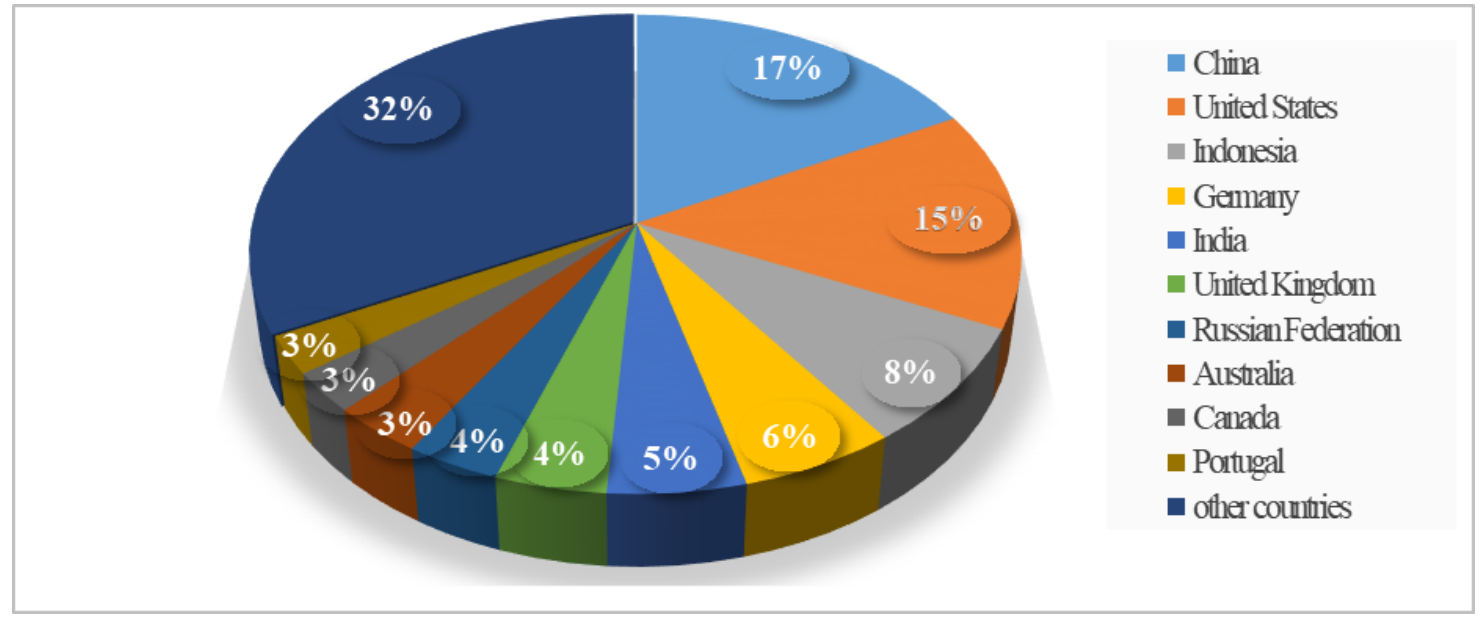

Figure 1. Top 10 effective countries in the MIS field

\subsection{Source Types}

Table 3 shows that almost $37 \%$ of the overall documents were articles derived from several MIS academic journals ( $\mathrm{n}=1346$ paper) found in Scopus, while conference papers published in the Journals constituted $(\mathrm{n}=1732)$ and book chapters constituted $(\mathrm{n}=439)$ of the total MIS publications. Other documents including reviews, letters, editorials, notes, short surveys, and so on, make up 3.1\% and lower of the overall publications.

Table 3. Source Types

\begin{tabular}{|l|c|c|}
\hline \multicolumn{1}{|c|}{ Source Type } & Frequency & Percentage \\
\hline Conference Proceedings & 1732 & $47.8 \%$ \\
\hline Academic Journals & 1346 & $37.1 \%$ \\
\hline Book Series & 439 & $12 \%$ \\
\hline Other sources & 107 & $3.1 \%$ \\
\hline Total & $\mathbf{3 6 2 4}$ & $\mathbf{1 0 0 \%}$ \\
\hline
\end{tabular}

\subsection{The top funding institutions}

In Figure 2, the funding sponsors of MIS institutions are presented. The National Natural Science Foundation of China is ranked as the top institutional sponsor followed by the European Commission, the National Science Foundation in third place and the European Regional Development Fund in fourth place. The top 10 funding bodies are shown in Figure 2. 


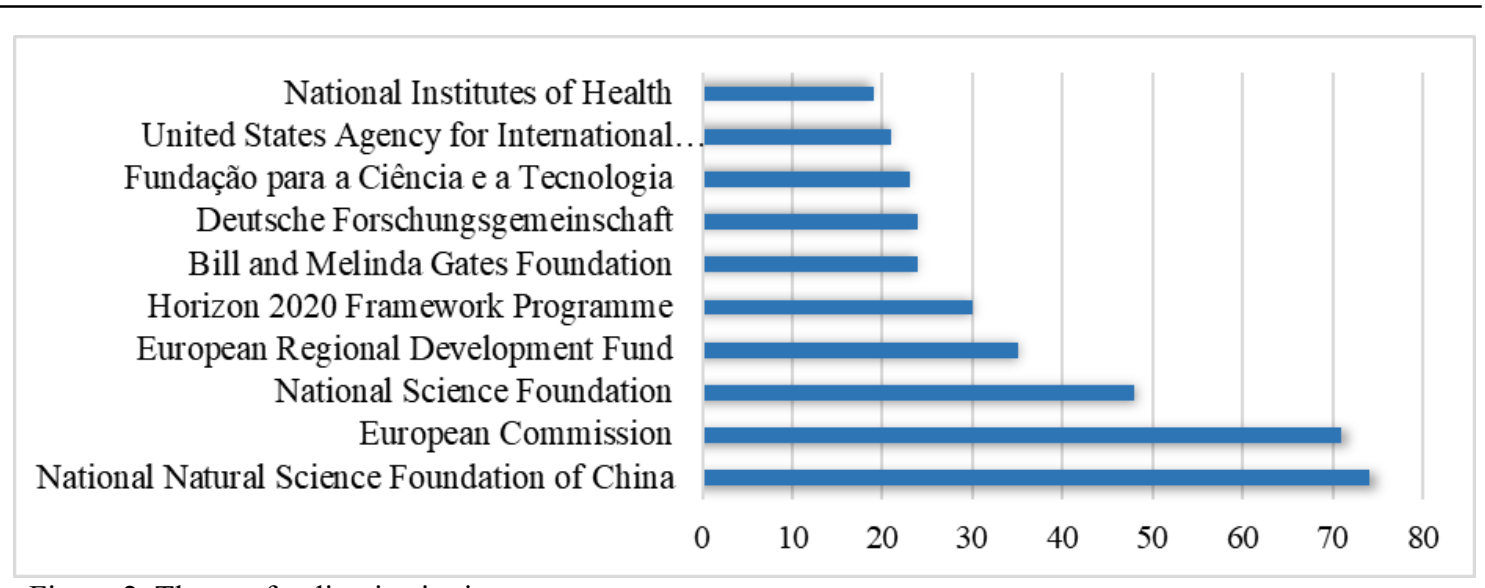

Figure 2. The top funding institutions

\subsection{Languages of documents}

A total of 15 languages were employed in MIS articles including English, Chinese and German. Table 4 shows that the top major language used is English at $92 \%$, indicating the need for researchers worldwide to communicate in one shared language, thereby enabling them to access information published globally (Di Bitetti et al., 2017).

Table 4. Languages of documents

\begin{tabular}{|l|c|c|}
\hline \multicolumn{1}{|c|}{ Language } & Frequency & Percentage \\
\hline English & 3341 & $92.19 \%$ \\
\hline Chinese & 143 & $3.95 \%$ \\
\hline German & 58 & $1.6 \%$ \\
\hline Portuguese & 33 & $0.91 \%$ \\
\hline Spanish & 24 & $0.66 \%$ \\
\hline Russian & 7 & $0.19 \%$ \\
\hline French & 4 & $0.11 \%$ \\
\hline Turkish & 4 & $0.11 \%$ \\
\hline Japanese & 3 & $0.08 \%$ \\
\hline Italian & 2 & $0.06 \%$ \\
\hline Others & 5 & $0.14 \%$ \\
\hline Total & $\mathbf{3 6 2 4}$ & $\mathbf{1 0 0 \%}$ \\
\hline
\end{tabular}

\subsection{Subject area}

Based on all the papers collected from the Scopus database, MIS covers almost all subject areas thus indicating a great diversity linked to the research topic of MIS in Scopus. Figure 3 presents publication counts for the top 10 subject areas for the current study period. The obtained data show that most works in this field are concentrated in Computer Science (31\%), Engineering (14\%), Decision Sciences (9\%), in Medicine (8\%), and in Business, Management and Accounting (8\%). These results are considered as inseparable parts, as a specialist of MIS should be knowledgeable on the issues of management while being well-informed about the fundamental subjects of computer and industrial field. Furthermore, this emphasizes the importance and applicability of the MIS in several areas, and especially in the four classical ones (i.e., Computer, Engineering, Medicine, and Management Sciences). 


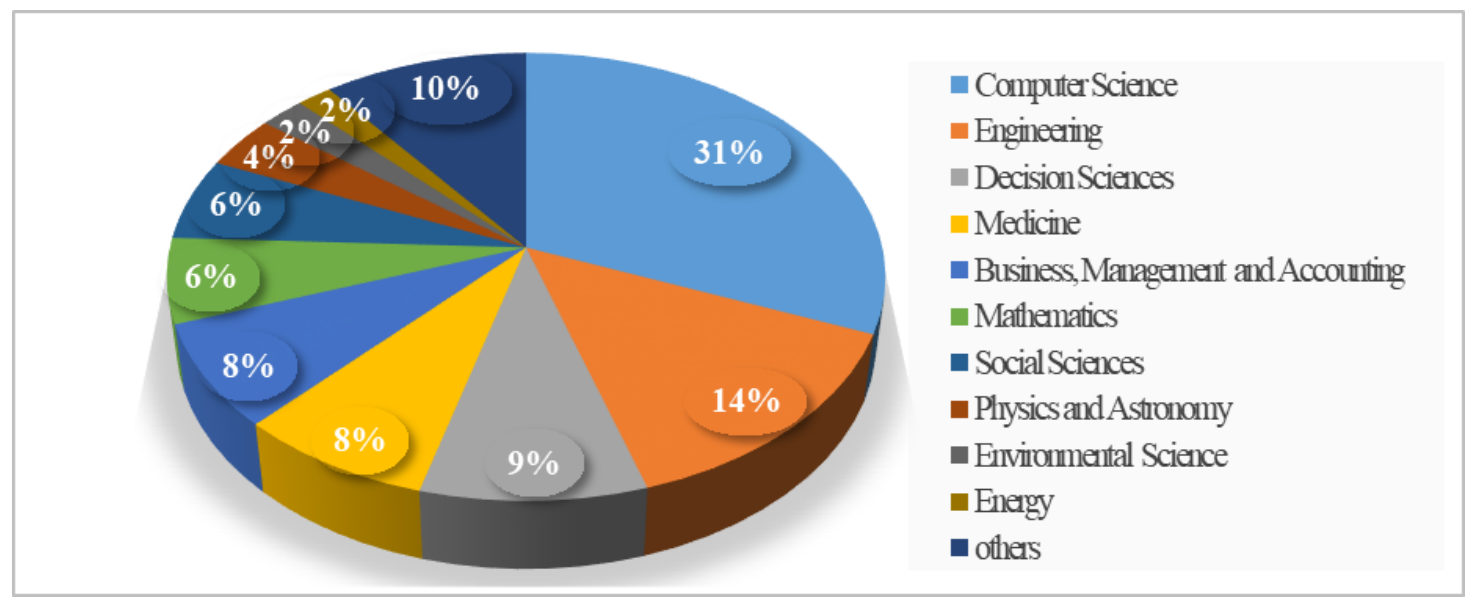

Figure 3. Distributions of MIS studies by subject areas

\section{Conclusion}

The MIS field has been experiencing advancements toward fulfilling the business and marketing milieu's changing requirements; hence, this study revealed the current developments in this field. This study presents a bibliometric review to gain a clearer insight into the development of MIS literature, by analyzing top MIS journals, effective authors, effective countries, document types, top funding institutions, document languages, and subject areas. Based on the results concerning the literature geographic dispersion, China has the highest number of publications, in comparison to the U.S. and Germany, with majority of the articles being in English language as journals and conferences publications. The Journal of Physics had the most publications related to MIS field, while the three major parts of the MIS field from the review are computer science, industrial engineering and decision science. Hence, this current study is expected to serve as an important platform for future research.

It is important to acknowledge several limitations to the study, with the first one being that the focus of the study is mainly laid on articles whose publication dates varied from 2017 to 2021, and thus, studies before 2017 were excluded in the analysis. Another limitation pertains to the exclusion of extensive scholarly journals and global conferences that were not included in Scopus database. Lastly, the study is limited in relation to the keywords selected that may have limited the process of data collection, as there are additional studies that may not have contained the keywords in their titles, abstracts or keyword search. Such studies may have had different focus on the MIS field, with the authors using varying terminologies to describe their studies and thus, the search process may have missed them. As such, it is important for future studies to extend the examined sources to include papers and documents from various database sources like Google Scholar. Furthermore, a more comprehensive research search using other applicable keywords is required to generate more relevant results.

\section{References}

Adeoti-Adekeye, W.B. (1997). The importance of management information systems. Library Review, 46(5), 318-327.

Ahmi, A., Elbardan, H., \& Ali, R. (2019). Bibliometric analysis of published literature on industry 4.0. In Proceedings of the International Conference on Electronics, Information, and Communication (ICEIC). IEEE, 1-6.

Albort-Morant, G., Henseler, J., Leal-Milla'n, A., \& Cepeda- Carri, G. (2017). Mapping the field: A bibliometric analysis of green innovation. Sustainability, 9(6), 1-7.

Al-Kofahi, M. K., Hassan, H., \& Mohamad, R. (2020). Information systems success model: A review of literature. International Journal of Innovation, Creativity and Change, 12(8), 397-419.

Barki, H., Rivard, S., \& Talbot, J. (1993). A keyword classification scheme for IS research literature: An update. MIS Quarterly, 17(2), 209-226. 
Culnan, M. J., \& Swanson, E. B. (1986). Research in management information systems, 1980-1984: Points of work and reference. MIS Quarterly, 10(3), 289-302.

Culnan, M. J. (1987). Mapping the intellectual structure of MIS, 1980-1985: A co-citation analysis. MIS Quarterly, 11(3), 341-353.

Di Bitetti, M. S., \& Ferreras, J. A. (2017). Publish (in English) or perish: The effect on citation rate of using languages other than English in scientific publications. Ambio, 46(1), 121-127.

Diem, A., \& Wolter, S. C. (2013). The use of bibliometrics to measure research performance in education sciences. Research in higher education, 54(1), 86-114.

El-Ebiary, Y. A. B., Pathmanathan, P. R., Tarshany, Y. M. A., Jusoh, J. A., Aseh, K., Al Moaiad, Y., Al-Kofahi, M., Pande, b. \& Bamansoor, S. (2021). Determinants of customer purchase intention using Zalora mobile commerce application. In Proceedings of the 2nd International Conference on Smart Computing and Electronic Enterprise (ICSCEE). IEEE, pp. 159-163. Malaysia.

Hu, J., Liu, L. C., Koong, K. S., \& Fok, L. (2002). Information systems journals: A study of university library holdings. Journal of Business \& Finance Librarianship, 8(1), 27-43.

Ives, B., Hamilton, S., \& Davis, G. (1980). A framework for research in computer-based management information systems. Management Science, 26(9), 910-934.

Katerattanakul, P., Han, B., and Rea, A. (2006). Is information system a reference discipline?. Communications of the ACM, 49(5), 114-1148.

Kofahe, M. K., Hassan, H., \& Mohamad, R. (2019). Factors affecting successful implementation of government financial management information system (GFMIS) in Jordan public sector: a proposed framework. International Journal of Accounting, Finance and Business (IJAFB), 4(20), 32-44.

La Paz, A., Merigo, J. M., Powell, P., Ramaprasad, A., \& Syn, T. (2020). Twenty-five years of the Information Systems Journal: A bibliometric and ontological overview. Information Systems Journal, 30(3), 431457.

Martinez-Lopez, F.J., Merigo, J.M., Valenzuela-Ferna'ndez, L. \& Nicola' s, C. (2018). Fifty years of the European journal of marketing: a bibliometric analysis. European Journal of Marketing, 52 (1/2), 439468.

Martin-Martin, A., Orduna-Malea, E., Thelwall, M., \& López-Cózar, E. D. (2018). Google Scholar, Web of Science, and Scopus: A systematic comparison of citations in 252 subject categories. Journal of Informetrics, 12(4), 1160-1177.

Merigo,' J. M., Pedrycz, W., Weber, R., \& de la Sotta, C. (2018). Fifty years of information sciences: A bibliometric overview. Information Sciences, 432, 245-268.

Mishra, L., Kendhe, R., \& Bhalerao, J. (2015). Review on management information systems (MIS) and its role in decision making. International Journal of Scientific and Research Publications, 5(10), 1-5.

Mohanty, B. (2014). Management Information Systems Quarterly (MISQ): A Bibliometric Study. Library Philosophy and Practice, 1-16.

Mohanty, B., \& Sahoo, J. (2016). The intellectual patterns of management information system research: a bibliometric study on International Journal of Management Reviews. Library Philosophy and Practice (e-journal), 1-16.

Özköse, H., \& Gencer, C. T. (2017). Bibliometric analysis and mapping of management information systems field. Gazi University Journal of Science, 30(4), 356-371.

Palvia, P., Pinjani, P., \& Sibley, E. H. (2007). A profile of information systems research published in Information and Management. Information and Management, 44(1), 1-11.

Palvia, P., Mao, E., Salam, A.F \& Soliman, K, S. (2003) Management information systems research: what's there in a methodology?. Communications of the Association for Information Systems, 11, 289-309.

Pritchard, A. (1969). Statistical bibliography or bibliometrics. Journal of Documentation, 25(4), 348. 
Punjani, K. K., Kumar, V. R., \& Kadam, S. (2019). Trends of puffery in advertising-a bibliometric analysis. Benchmarking: An International Journal, 26(8), 2468-2485.

Straub, D., \& Anderson, C. (2010). Journal Quality and Citations: Common Metrics and Considerations About Their Use, MIS Quarterly, 34(1), iii-xii.

Zhai, X., Cui, J., Shao, J., Wang, Q., Chen, X., Wei, X., Zhou, X., Chen, Z., \& Li, M. (2017). Global research trends in spinal ultrasound: a systematic bibliometric analysis. BMJ open, 7(10), 1-7. 